\title{
Differential Expression of mRNA for Guanylyl Cyclase-linked Endothelium-derived Relaxing Factor Receptor Subunits in Rat Kidney
}

\author{
Kazatomo Ujiie, * James G. Drewett, ${ }^{* 5}$ Peter S. T. Yuen, ${ }^{* 5}$ and Robert A. Star* \\ Departments of *Internal Medicine, ${ }^{\ddagger}$ Pharmacology, and the ${ }^{\S}$ Howard Hughes Medical Institute, \\ University of Texas Southwestern Medical Center, Dallas, Texas 75235-8856
}

\begin{abstract}
Endothelium-derived relaxing factor (EDRF) has profound effects on the renal vasculature, the glomerular mesangium, and also affects renal salt excretion. EDRF stimulates guanylyl cyclases, which are thought to be heterodimers comprised of $\alpha$ and $\beta$ subunits. Two $\alpha$ and two $\beta$ isoforms have been identified thus far. However, the molecular composition of in vivo guanylyl cyclase-linked EDRF receptors is unknown. We used polymerase chain reaction to clone a portion of the rat $\alpha 2$ subunit. Guanylyl cyclase-linked EDRF receptor mRNA was detected in microdissected renal structures using a reverse transcription/polymerase chain reaction assay. The interlobular artery / afferent arteriole contained mRNA for the $\alpha 1, \alpha 2$, and $\beta 1$ subunits; a faint $\beta 2$ band was found in $29 \%$ of experiments. In contrast, the cortical collecting duct contained mRNA only for $\alpha 1$ and $\beta 2$ subunits.

We conclude that guanylyl cyclase-linked EDRF receptor subunit isoforms are independently and heterogeneously expressed in the renal vasculature and cortical collecting duct, suggesting that several different EDRF receptors exist in vivo. These data suggest that the tubule receptor is composed of $\alpha 1 / \beta 2$. The vasculature may contain at least two different EDRF receptors $(\alpha 1 / \beta 1$ and $\alpha 2 / \beta 1)$. Some $\beta 2$ may also be expressed, allowing for even greater heterogeneity. (J. Clin. Invest. 1993.91:730-734.) Key words: endothelium-derived relaxing factor receptor • soluble guanylyl cyclase • polymerase chain reaction $\bullet$ gene expression $\bullet$ blood vessels
\end{abstract}

\section{Introduction}

Endothelium-derived relaxing factor $(E D R F)^{1}$ is produced in endothelial cells and acts in vascular smooth muscle cells to produce vasodilation. As expected, EDRF has profound effects

Address correspondence to Robert Alan Star, M. D., Department of Internal Medicine/Nephrology, University of Texas Southwestern Medical Center, 5323 Harry Hines Boulevard, Dallas, TX 75235-8856. Received for publication 27 July 1992 and in revised form 20 October 1992.

1. Abbreviations used in this paper: $\mathrm{CCD}$, cortical collecting duct; EDRF, endothelium-derived relaxing factor; ILA/AA, interlobular artery/afferent arterioles.

J. Clin. Invest.

(C) The American Society for Clinical Investigation, Inc.

0021-9738/93/02/0730/05 \$2.00

Volume 91, February 1993, 730-734 on renal blood flow and glomerular filtration rate (reviewed in $[1,2])$. There is growing evidence that EDRF also affects renal sodium transport, since EDRF synthesis inhibitors alter renal salt excretion in the absence of hemodynamic effects $(3,4)$ and inhibit oxygen consumption in suspensions of outer medullary collecting ducts (5). EDRF also inhibits short circuit current, a marker for sodium transport, in cultured mouse cortical collecting duct (CCD) cells (6).

EDRF stimulates guanylyl cyclases, causing elevation of cyclic GMP concentration. Guanylyl cyclase-linked EDRF receptors, subsequently referred to as EDRF receptors, consist of two subunits ( $\alpha$ and $\beta$ ) and contain a heme group, the presumed recognition site for nitric oxide/EDRF (7-13). By convention, the longer subunit is denoted $\alpha$; the shorter subunit is denoted $\beta$ (14). At present, two $\alpha$ and two $\beta$ subunits have been cloned $(7,8,10,11,15)$. Although all $\alpha$ and $\beta$ subunits contain an apparent $\mathrm{COOH}$-terminal catalytic domain, they do not function independently $(8,11,16)$. Rather, co-expression of two subunits is required to reconstitute catalytic activity $(8,15,16)$.

From the limited data available, there is evidence of tissuespecific expression. While $\alpha 1$ and $\beta 1$ are expressed in many organs and tissues $(8,10)$, a second $\beta$-subunit $(\beta 2)$ cloned by Yuen, Potter, and Garbers from rat kidney is preferentially expressed in rat kidney and liver (15). Rat $\beta 2$ is $43 \%$ homologous to rat $\beta 1$ in the putative catalytic domain near the carboxyl terminus and $50 \%$ homologous to rat $\beta 1$ in an amino-terminal domain which may contain the heme binding site. Recently, a second $\alpha$ subunit ( $\alpha 2)$ was cloned from human brain; however, its tissue distribution is unknown (11). The tissuespecific distribution of $\beta 2$ suggests the existence of multiple EDRF receptor heterodimers. However, the specific cellular localization and the composition of in vivo heterodimers are unknown. We used the reverse transcriptase/polymerase chain reaction ( $R T$ / PCR) to localize the known EDRF receptor subunit isoforms in specific portions of the kidney. This method couples the fine structural resolution obtained with renal microdissection with the extreme sensitivity of PCR $(17,18)$.

\section{Methods}

Cloning of partial length rat $\alpha 2$ guanylyl cyclase subunit by degenerate $P C R$. CDNA was made from $1 \mu \mathrm{g}$ of poly $\mathrm{A}^{+}$RNA from rat olfactory mucosa (gift of Dr. Randall Reed, Johns Hopkins University, Baltimore, MD). RNA was denatured by heating to $65^{\circ} \mathrm{C}$ for $10 \mathrm{~min}$, then cooled on ice for $2 \mathrm{~min}$. Murine Moloney leukemia virus reverse transcriptase (BRL, Gaithersburg, MD) was added at a final concentration of $200 \mathrm{U} / \mu \mathrm{g}$, and tubes were incubated at $37^{\circ} \mathrm{C}$ for $1 \mathrm{~h}$. The reaction was stopped by ethanol precipitation. PCR with degenerate oligonucleotide primers directed at the guanylyl cyclase domain was carried out as 


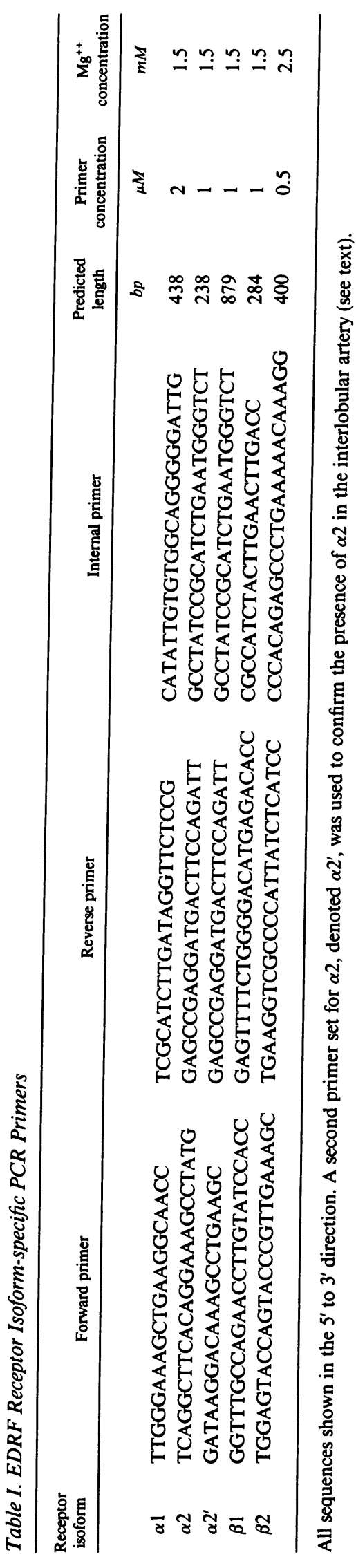

described previously (15). The sense oligonucleotide [ GGCGGATTCGGTACCGTITA(C/T)AA(G/A)GTIGA(G/A)ACI(G/A)TIGGIGA;5' to $3^{\prime}$ ] coded for amino acids VYKVET(V/I)GD; the antisense oligonucleotide [GCTATCTAGAGGATTC(G/A)AAIA(G/A)(G/A)CA(G/A)TAICIIGGCAT; 5' to 3'] coded for amino acids MPRYCLF. Both oligonucleotides contained a 15-bp polylinker as described previously (15). Inosine was used in positions of high $(>2)$ degeneracy. PCR products ( $230 \mathrm{bp}$ ) were cloned into a M13 vector. Screening of 32 clones by single track sequencing (Sequenase 2.0; U. S. Biochemical Corp., Cincinnati, $\mathrm{OH}$ ) yielded a guanylyl cyclase which had a $72 \%$ amino acid homology to rat $\alpha 1$. Additional 5 ' sequence information was cloned from rat lung CDNA using PCR with a degenerate oligonucleotide primer directed to a consensus amino acid sequence [FC(D/ $\mathrm{K})(\mathrm{A} / \mathrm{T}) \mathrm{FPF}]$ found in the $5^{\prime}$ end of the molecule, and additional $3^{\prime}$ sequence was obtained by $3^{\prime}$ RACE PCR (19). These pieces were subcloned and sequenced from both ends. The deduced amino acid sequence was $95 \%$ identical to the recently reported human $\alpha 2$ (11).

Isolated nonperfused tubules and blood vessels. We isolated vascular and nephron segments from pathogen-free Sprague Dawley rats $(90-120 \mathrm{~g})$ as previously described (20). The kidneys were perfused with $1 \mathrm{mg} / \mathrm{ml}$ collagenase and $0.05 \%$ BSA. Cortical slices were incubated with collagenase for $15-40 \mathrm{~min}$ at $37^{\circ} \mathrm{C}$ in a Hepes-buffered solution (in mM: $\mathrm{NaCl} 125, \mathrm{KCl} 5$, Hepes $5, \mathrm{Na}$ acetate $3, \mathrm{CaCl}_{2} 2$, MgSulfate 1.2, $\mathrm{NaH}_{2} \mathrm{PO}_{4} 1$, glucose 5.5, L-alanine 6, L-glutamine 1; $\mathrm{pH}$ adjusted to 7.4 with $\mathrm{NaOH}$ ). Specific vascular and nephron segments were dissected at $15^{\circ} \mathrm{C}$. Tubule lengths were measured with a calibrated eyepiece micrometer. Because previous studies identified the afferent arteriole as a target of EDRF, we developed a technique to dissect rat blood vessels. Interlobular arteries with attached afferent arterioles (ILA/AA) were dissected by grasping an arcuate blood vessel with the left hand and carefully stripping away adherent tubules and glomeruli with the right hand. The length of the interlobular artery was recorded; the lengths of the attached afferent arterioles were not recorded.

Detection of EDRF receptor $m R N A$ in renal tubules and blood vessels. We used the RT/PCR technique of Moriyama $(17,18)$, with slight modifications to allow four parallel reactions on the same cDNA sample. Microdissected tubules $(20-40 \mathrm{~mm})$ or blood vessels $(8 \mathrm{~mm})$ were transferred by an albumin-coated $200-\mu$ l pipette tip to a wash solution to rinse away debris. Wash solutions were placed in disposable plastic dishes (Corning Inc., Corning, NY) to minimize contamination. The segments were attached to $.25-\mathrm{mm}$ glass beads ( Thomas Scientific, Swedesboro, NJ), then transferred using a forceps to a 500- $\mu 1$ reaction tube. To minimize cross-contamination of mRNA from tubules to blood vessels, the dissection and wash solutions did not contain RNAse inhibitors. The segments were rinsed four times with icecold dissection solution containing an RNase inhibitor (RNasin, $1 \mathrm{U} /$ $\mu \mathrm{l}$; Promega Corp., Madison, WI), then permeabilized with $2 \%$ Triton $\mathrm{X}-100$ in the presence of RNase inhibitor. cDNA synthesis was carried out using $200 \mathrm{U}$ murine Moloney leukemia virus reverse transcriptase, $5 \mu \mathrm{M}$ oligo-dT ${ }_{16}, 1 \mathrm{mM} \mathrm{dNTPs,} \mathrm{and} 3 \mathrm{mM} \mathrm{Mg}^{++}$in a volume of $20 \mu \mathrm{l}$. In some tubes, the reverse transcriptase was omitted to control for amplification from contaminating cDNA or genomic DNA. The temperature profile was: $(a)$ annealing at room temperature for $5 \mathrm{~min},(b)$ extension at $42^{\circ} \mathrm{C}$ for $60 \mathrm{~min}$, and $(c)$ termination at $99^{\circ} \mathrm{C}$ for $5 \mathrm{~min}$.

The resulting segment-specific cDNA was split into four tubes, and PCR was performed using specific oligonucleotide primers and conditions indicated in Table I. PCR reactions contained: .5-2 $\mu \mathrm{M}$ primers, $1.5-2.5 \mathrm{mM} \mathrm{Mg}^{++}, 200 \mu \mathrm{M}$ dNTPs, reaction buffer, and $2 \mu \mathrm{l} \mathrm{cDNA}$ in $48 \mu$ l. The sample was overlaid with $75 \mu$ l silicone oil (.05 stokes; Dow Corning Corp., Midland, MI). To minimize nonspecific amplification, we employed a "hot start" procedure whereby PCR samples were placed in a thermal cycler (Perkin Elmer Cetus, Norwalk, CT) prewarmed to $94^{\circ} \mathrm{C}$. After 2 min, each tube was opened sequentially and $2.5 \mathrm{U}$ (in $2 \mu \mathrm{l}$ ) of TaqDNA polymerase (Promega Corp.) was added. The PCR temperature profile consisted of 35 cycles of $94^{\circ} \mathrm{C}$ for $30 \mathrm{~s}$ (denaturation), $58^{\circ} \mathrm{C}$ for $15 \mathrm{~s}$ (annealing), and $72^{\circ} \mathrm{C}$ for $1.25 \mathrm{~min}$ (extension), followed by an additional $5 \mathrm{~min}$ final extension at $72^{\circ} \mathrm{C}$. Optimal annealing temperature was determined from nearest neighbor 
free energy considerations (21) using a computer program written by the authors. We optimized the primer location, primer concentration, $\mathrm{Mg}^{++}$, and annealing temperature, for each primer set to produce the greatest amount of a single PCR product.

The PCR products were size-fractionated by agarose gel electrophoresis. The DNA was transferred to nylon filters, and probed with a ${ }^{32}$ P-end-labeled internal oligonucleotide primer specific for each subunit. The prehybridization, hybridization, and washing conditions were similar to Garcia-Perez et al. (22). Our subunit specific oligonucleotide probes do not cross-hybridize with the other known subunits.

Potential PCR primers were chosen from rat sequence information using the method of Lowe et al. (23). To prevent amplification of other known guanylyl cyclases, nonspecific annealing of the 3 ' end of each primer with other EDRF receptor subunits and the ANP A and B receptors $(15,24,25)$ was checked using specially written computer software. The location of intron/exon boundaries for the EDRF receptor isoforms are unknown. PCR primers were shown to be in separate exons by the absence of the predicted PCR product $(a)$ in samples containing $1 \mu \mathrm{g}$ of rat genomic DNA (data not shown), or $(b)$ in samples containing blood vessels or tubules but lacking reverse transcriptase (see Figs. 1 and 2). Each primer set produced a single band of the predicted size on both agarose gels and on Southern blots (Figs. 1 and 2 ). The $\beta 1$ primer set produces a higher molecular weight product, which presumably contains at least one intron. The higher molecular weight $\beta 1$ band is seen in reactions using $1-2-\mathrm{mm}$ tubule, indicating that the $\beta 1$ primer set is extremely sensitive (i.e., can detect $\sim 1,000$ template molecules in $\sim 500$ cells).

Direct sequencing of PCR products. DNA excised from an agarose gel band was purified by glass beads, then subjected to direct double stranded sequencing ( $\mathrm{fmol}$ PCR sequencing; Promega Corp.). We used the isoform-specific PCR primers as sequencing primers. The DNA was sequenced for 100-200 bp in each direction.

cGMP accumulation. cGMP accumulation was measured as described previously (26). Microdissected arteries were incubated for 10 min at $37^{\circ} \mathrm{C}$ with $0.5 \mathrm{mM}$ 3-isobutyl-1-methylxanthine in dissection solution. Nitroprusside (final concentration $100 \mu \mathrm{M}$ ) or vehicle was added for $3 \mathrm{~min}$. The incubation was terminated with ice-cold TCA, and the supernatant was stored at $-70^{\circ} \mathrm{C}$. The TCA was removed with water-saturated ether, and cGMP content was measured by radioimmunoassay (New England Nuclear, Boston, MA). In each experiment, $a 1$
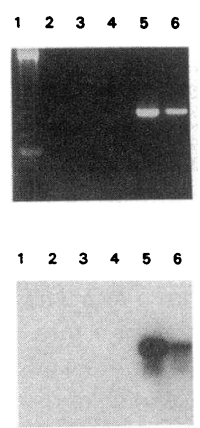

B1
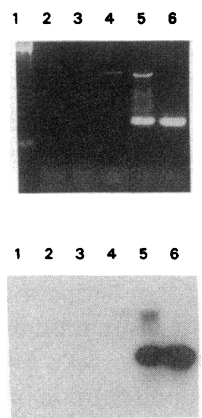

a2
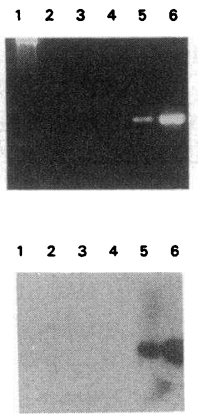

B2
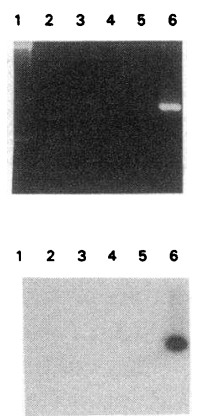

Figure 1. Ethidium bromide-stained gel (top) and Southern blot (bottom) of RT/PCR products from rat interlobular artery/afferent arterioles. (Lane 1) 123-bp mol wt markers. (Lane 2) glass bead-reverse transcriptase. (Lane 3) glass bead + reverse transcriptase. (Lane 4) $2 \mathrm{~mm}$ ILA/AA without reverse transcriptase. (Lane 5) $2 \mathrm{~mm}$ ILA/AA + reverse transcriptase. (Lane 6) positive control. Southern blots were processed as indicated in Methods. Band sizes were: $\alpha 1$, $438 \mathrm{bp} ; \alpha 2,238 \mathrm{bp} ; \beta 1,284 \mathrm{bp} ; \beta 2,400 \mathrm{bp}$. The larger band $(1,100$ bp) in the $\beta 1$ reactions was produced from genomic DNA. These results are representative of five independent experiments; in two additional experiments, $\beta 2$ was barely detectable.

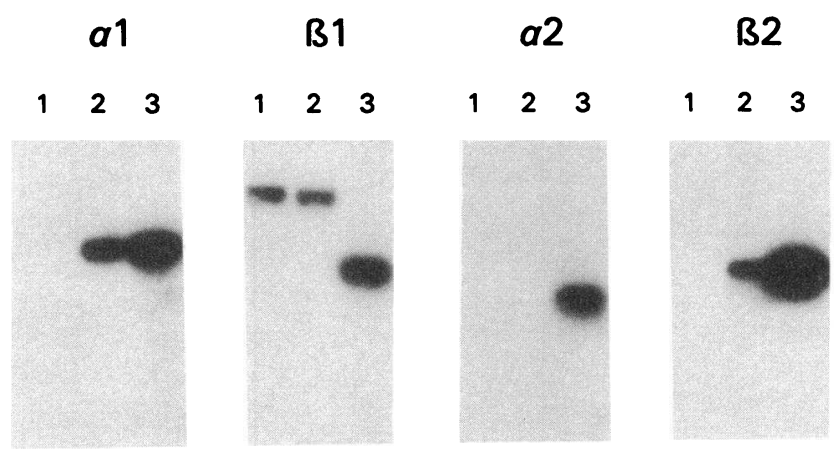

Figure 2. Southern blot of RT / PCR products from rat cortical collecting duct. (Lane 1) $2 \mathrm{~mm}$ CCD without reverse transcriptase. (Lane 2) $2 \mathrm{~mm} \mathrm{CCD} \mathrm{+} \mathrm{reverse} \mathrm{transcriptase.} \mathrm{(Lane} \mathrm{3)} \mathrm{positive} \mathrm{con-}$ trol. Band sizes are as described in Fig. 1. These results are representative of four independent experiments.

blank samples containing medium and TCA without arteries were also taken. Each point is the mean of four tubes.

Statistics. The results are given as means \pm SE. The differences were tested by unpaired $t$ test. $P<0.05$ was considered significant.

\section{Results}

Differential expression of EDRF receptor subunit mRNA by $R T / P C R$ in microdissected rat renal structures. Fig. 1 shows a typical ethidium bromide stained agarose gel (top) and Southern blot analysis (bottom) of the RT / PCR amplification products from EDRF receptor subunit isoform mRNA in microdissected interlobular artery with attached afferent arteries. We consistently found the presence of $\alpha 1, \alpha 2$, and $\beta 1$ on ethidium bromide-stained gels and on Southern blots. We were surprised to find $\alpha 2$ by RT/PCR, since $\alpha 2$ could not be detected by Northern blotting using $30 \mu \mathrm{g}$ of poly- $\mathrm{A}^{+}$RNA (data not shown). To confirm that $\alpha 2$ was present in this vascular segment, we performed RT/PCR using a second set of $\alpha 2$ primers. This primer set produced an 879-bp band of the correct predicted size, which hybridized to an internal oligonucleotide probe (results not shown). This confirms that $\alpha 2$ is present in the interlobular artery/afferent arteriole. A similar pattern of subunit expression was found in microdissected arcuate arteries. We also detected a very faint band for $\beta 2$ by both ethidium bromide stained agarose gels and by Southern blotting in 2 of 7 independent experiments in ILA/AA. We did not detect any $\beta 2$ mRNA in three similar experiments using 1-2$\mathrm{mm}$ arcuate blood vessels.

Fig. 2 shows a Southern blot analysis of the RT/PCR amplification products from microdissected cortical collecting duct. We found that mRNA for $\alpha 1$ and $\beta 2$ were present in rat CCD. In contrast, we could not detect $\alpha 2$ or $\beta 1$.

Direct double-stranded sequencing of the specific bands generated from microdissected renal structures indicated that the bands were identical to published sequences for rat $\alpha 1, \beta 1$, and $\beta 2$. Partial sequence of the bands produced from both sets of $\alpha 2$ primers was identical to the sequence of $\alpha 2$ cloned from rat olfactory mucosa.

cGMP accumulation. $100 \mu \mathrm{M}$ nitroprusside significantly increased cGMP accumulation in interlobular artery/afferent arterioles ( $124 \pm 17$ to $413 \pm 83 \mathrm{fmol} / 4 \mathrm{~mm}$ per $3 \mathrm{~min}$ ), indicating the presence of a functional guanylyl cyclase-linked EDRF receptor. 


\section{Discussion}

These studies provide the first evidence that mRNA for different guanylyl cyclase-linked EDRF receptor subunits are heterogeneously expressed in renal blood vessels and the cortical collecting duct (Table II). We also report a method for detecting several genes simultaneously. Previous studies using an RT/ PCR technique to detect gene expression in microdissected renal structures have only detected one gene at a time. We will discuss several technical issues, then discuss the implications of the results.

Specificity of PCR primers. We placed all PCR primers near the 3 ' end of the coding sequences, since this would maximize detection of cDNA transcripts prepared using oligo-dT primers. However, the four EDRF receptor subunits all contain a putative guanylyl cyclase catalytic domain at their carboxy terminus, which shares high homology with a similar region contained in the membrane bound guanylyl cyclase receptors (including ANP and heat-stable enterotoxin [11, 14]). We developed computer software to find the regions of highest mismatch between similar genes. To minimize the possibility of detecting the wrong gene, we were careful to locate the PCR primers in unique regions. For example, the forward primers for $\alpha 2, \beta 1$, and $\beta 2$ were placed in the same low homology region within the presumed guanylyl cyclase catalytic site, while the reverse primers for $\beta 1$ and $\beta 2$ were placed in their unique carboxy terminus regions. We confirmed that the PCR products were indeed from the desired genes by two different methods: $(a)$ We used Southern blotting with an internal oligonucleotide probe synthesized to an unique region of each isoform. This technique ensures that the PCR product contains an additional 20-25 bases of identity to the intended product. ( $b$ ) More strict evidence was obtained by directly sequencing several hundred bases of each band. In all cases, the sequences agreed with those previously published for $\alpha 1, \beta 1$, and $\beta 2$. The deduced amino acid sequence of the $\alpha 2$ band agreed with the published sequence of human $\alpha 2$. Taken together, these results establish that the PCR primers were specific for the desired genes.

Molecular composition of heterodimeric guanylyl cyclaselinked EDRF receptors. By performing four PCR reactions in parallel on the same sample, we were able to co-localize the expression of EDRF receptor subunits. This is important, since the guanylyl cyclase-linked EDRF receptor is a heterodimer. When expressed alone, all four subunits are inactive, and not stimulated by nitroprusside $(8,11,15,16)$. Co-expression of $\alpha 1 / \beta 1$ or $\alpha 2 / \beta 1$ results in enzyme which is stimulated by nitroprusside $(8,11,16)$, suggesting that dimerization is required for formation of an active catalytic site. Thus, at least several different heterodimeric EDRF receptors could exist in vivo:

Table II. Differential Expression of Guanylyl Cyclase-linked EDRF Receptor Subunit Isoforms

\begin{tabular}{ccccc}
\hline Location & $\alpha 1$ & $\alpha 2$ & $\beta 1$ & $\beta 2$ \\
\hline Interlobular artery/ & & & & \\
afferent arteriole & + & + & + & Faint* \\
Cortical collecting duct & + & - & - & + \\
\hline
\end{tabular}

* Detected in only two of seven experiments. i.e., $\alpha 1 / \beta 1, \alpha 2 / \beta 1, \alpha 1 / \beta 2$, and $\alpha 2 / \beta 2$. The first two are known the be active in vitro expression systems; the other combinations have yet to be tested. Our results strongly suggest that several different EDRF receptors exist in vivo, and suggest that tubule receptor is composed of $\alpha 1 / \beta 2$. Since we have only detected mRNA expression, the existence of $\alpha 1 / \beta 1, \alpha 1 / \beta 2$, and $\alpha 2 / \beta 1$ heterodimers must be determined at the protein level. Whether these different heterodimers possess different sensitivity to EDRF or other EDRF analogues, or function differently, is unknown. In this regard, it is interesting that the $\beta 2$ subunit contains a carboxy terminus consensus isoprenylation sequence ( $C-V-V-L)$, which, if isoprenylated, could allow $\beta 2$ to associated with a cell membrane (15).

The composition of the vascular EDRF receptor(s) is uncertain. While it is usually assumed that EDRF is synthesized in the endothelium and acts in vascular smooth muscle, recent studies have suggested that endothelial cells also contain an EDRF receptor (27) whose function is unknown. Our results show that the afferent arteriole/interlobular artery has guanylyl cyclase activity, and contains mRNA for the $\alpha 1, \alpha 2$, and $\beta 1$ EDRF receptor subunit isoforms. In addition, the afferent artery/interlobular artery may also weakly express $\beta 2$. Terada et al. found that the arcuate artery weakly expressed $\beta 2$ (28). The molecular identity of the endothelial and vascular smooth muscle EDRF receptor(s) would be of interest. However, we cannot answer this question since the vascular tissue dissected in this study contains endothelium and vascular smooth muscle cells. In particular, it would be of interest to determine if $\alpha 2$ is expressed in both cell types, or only one cell type. If all three receptor isoforms are simultaneously expressed in one cell, this raises the intriguing possibility that the level of $\alpha 2$ could modulate guanylyl cyclase activity. Indeed, a recent study has shown that human $\alpha 2$ /bovine $\beta 1$ heterodimer appears less active than a bovine $\alpha 1$ /bovine $\beta 1$ heterodimer (11). It is uncertain whether this is caused by intrinsic differences in enzyme activity, subtle species differences, or unequal expression of $\alpha 1 / \beta 1$ vs $\alpha 2 / \beta 1$.

Expression of mRNA for the $\alpha 2$ EDRF receptor was easily detected by RT/PCR in microdissected interlobular arteries/ afferent arterioles (Fig. 2), but not by Northern blotting with random-hexamer primed probes. Northern blotting may not detect gene expression if the message is of low abundance, or localized to a rare compartment. Because of its high sensitivity, PCR is routinely employed to detect gene expression of rare transcripts. These studies show the synergistic methods of microdissection and PCR can be used to localize mRNA species expressed in small portions of an organ.

Nitroprusside-stimulated cGMP accumulation has been detected in microdissected rat CCD and cultured mouse CCD cells $(6,29)$. Recently, EDRF released from endothelial cells decreased the short-circuit current in mouse CCD cells (6). Taken together, these studies indicate that the CCD contains a functional EDRF receptor which is comprised of $\alpha 1 / \beta 2$ subunits. Activation of this receptor could modulate salt transport, although this has not been formally tested in the intact CCD.

Conclusions. We conclude that guanylyl cyclase-linked EDRF receptor subunit isoforms are independently and heterogeneously expressed in the renal vasculature and cortical collecting duct. These results strongly suggest that several different EDRF receptors exist in vivo, and suggest that the tubule receptor is composed of $\alpha 1 / \beta 2$. The identity of the endothelial and vascular smooth muscle cell receptors are unknown. Future 
co-expression studies should be useful in determining if these EDRF receptors exhibit different sensitivity to EDRF and related compounds, or subserve different functions.

\section{Acknowledgments}

We thank Dr. David Garbers for helpful discussions, Laurie Hogarth for excellent technical assistance, and Drs. Robert Alpern, Christine Baylis, and Diana Marver for their careful review of the manuscript.

This study was supported by National Institutes of Health grant DK-01888-01, and a grant-in-aid from the American Heart Association.

\section{References}

1. King, A. J., and B. M. Brenner. 1991. Endothelium-derived vasoactive factors and the renal vasculature. Am. J. Physiol. 260:R653-R662.

2. Romero, J. C., V. Lahera, M. G. Salom, and M. L. Biondi. 1992. Role of endothelium-derived relaxing factor nitric oxide on renal function. J. Am. Soc. Nephrol. 2:1371-1387.

3. Lahera, V., M. G. Salom, F. Miranda-Guardiola, S. Moncada, and J. C. Romero. 1991. Effects of Ng-nitro-L-arginine methyl ester on renal function and blood pressure. Am. J. Physiol. 261:F1033-F1037.

4. Lahera, V., M. G. Salom, M. J. Fiksen-Olsen, and J. C. Romero. 1991. Mediatory role of endothelium-derived nitric oxide in renal vasodilatory and excretory effects of bradykinin. Am. J. Hypertens. 4:260-262.

5. Neuringer, J., M. Zeidel, J. L. Troy, M. Zayas, G. Otuchere, and B. M. Brenner. 1991. $\mathrm{N}_{\mathrm{w}}$-nitro-L-arginine methyl ester inhibits renal sodium transport in vivo and in vitro. J. Am. Soc. Nephrol. 2:510. (Abstr.)

6. Stoos, B. A., O. A. Carretero, R. D. Farhy, G. Scicli, and J. L. Garvin. 1992. Endothelium-derived relaxing factor inhibits transport and increases cGMP content in cultured mouse cortical collecting duct cells. J. Clin. Invest. 89:761-765.

7. Koesling, D., J. Herz, H. Gausepohl, F. Niroomand, K.-D. Hinsch, A. Mulsch, E. Bohme, G. Schultz, and R. Frank. 1988. The primary structure of the $70 \mathrm{kDa}$ subunit of bovine soluble guanylate cyclase. FEBS (Fed. Eur. Biochem. Soc.) Lett. 239:29-34.

8. Nakane, M., K. Arai, S. Saheki, T. Kuno, W. Buechler, and F. Murad 1990. Molecular cloning and expression of cDNAs coding for soluble guanylate cyclase from rat lung. J. Biol. Chem. 265:16841-16845.

9. Koesling, D., C. Harteneck, P. Humbert, A. Bosserhoff, R. Frank, G. Schultz, and E. Bohme. 1990. The primary structure of the larger subunit of soluble guanylyl cyclase from bovine lung: homology between the two subunits of the enzyme. FEBS (Fed. Eur. Biochem. Soc.) Lett. 266:128-132.

10. Nakane, M., S. Saheki, T. Kuno, K. Ishii, and F. Murad. 1988. Molecular cloning of a cDNA coding for 70 kilodalton subunit of soluble guanylate cyclase from rat lung. Biochem. Biophys. Res. Commun. 157:1139-1147.

11. Harteneck, C., B. Wedel, D. Koesling, J. Malkewitz, E. Bohme, and G. Schultz. 1991. Molecular cloning and expression of a new $\alpha$-subunit of soluble guanylyl cyclase: interchangeability of the $\alpha$-subunits of the enzyme. FEBS (Fed. Eur. Biochem. Soc.) Lett. 292:217-222.

12. Ignarro, L. J., J. B. Adams, P. M. Horwitz, and K. S. Wood. 1986. Activa- tion of soluble guanylate cyclase by NO-hemoproteins involves NO-heme exchange. J. Biol. Chem. 261:4997-5002.

13. Ignarro, L. J. 1991. Signal transduction mechanisms involving nitric oxide. Biochem. Pharmacol. 41:485-490.

14. Yuen, P. S. T., and D. L. Garbers. 1992. Guanylyl cyclase-linked receptors. Annu. Rev. Neurosci. 15:193-225.

15. Yuen, P. S. T., L. R. Potter, and D. L. Garbers. 1990. A new form of guanylyl cyclase is preferentially expressed in rat kidney. Biochemistry. 29:10872-10878.

16. Harteneck, C., D. Koesling, A. Soling, G. Schultz, and E. Bohme. 1990. Expression of soluble guanylyl cyclase: catalytic activity requires two enzyme subunits. FEBS (Fed. Eur. Biochem. Soc.) Lett. 272:221-223.

17. Moriyama, T., H. R. Murphy, B. M. Martin, and A. Garcia-Perez. 1990. Detection of specific mRNAs in single nephron segments by use of the polymerase chain reaction. Am. J. Physiol. 258:F1470-F1474.

18. Terada, Y., T. Moriyama, B. M. Martin, M. A. Knepper, and A. GarciaPerez. 1991. RT-PCR micro-localization of mRNA for guanylyl cyclase-coupled ANF receptor in rat kidney. Am. J. Physiol. 261:F1080-F1087.

19. Frohman, M. A., M. K. Dush, and G. R. Martin. 1988. Rapid production of full-length cDNAs from rare transcripts: amplification using a single gene-specific oligonucleotide primer. Proc. Natl. Acad. Sci. USA. 85:8998-9002.

20. Star, R. A., H. Nonoguchi, R. Balaban, and M. A. Knepper. 1988. Calcium and cyclic adenosine monophosphate as second messengers for vasopressin in the rat inner medullary collecting duct. J. Clin. Invest. 81:1879-1888.

21. Rychlik, W., W. J. Spencer, and R. E. Rhoads. 1990. Optimization of the annealing temperature for DNA amplification in vitro. Nucleic Acids Res. 18:6409-6412.

22. Garcia-Perez, A., B. Martin, H. R. Murphy, S. Uchida, H. Murer, B. D. Cowley, Jr., J. S. Handler, and M. B. Burg. 1989. Molecular cloning of cDNA coding for kidney aldose reductase. Regulation of specific mRNA accumulation by NaCl-mediated osmotic stress. J. Biol. Chem. 264:16815-16821.

23. Lowe, T., J. Sharef kin, S. Q. Yang, and C. W. Dieffenbach. 1990. A computer program for selection of oligonucleotide primers for polymerase chain reactions. Nucleic Acids Res. 18:1757-1761.

24. Chinkers, M., D. L. Garbers, M.-S. Chang, D. G. Lowe, H. Chin, D. V Goeddel, and S. Schulz. 1989. A membrane form of guanylate cyclase is an atria natriuretic peptide receptor. Nature (Lond.). 338:78-83.

25. Schulz, S., S. Singh, R. A. Bellet, G. Singh, D. J. Tubb, H. Chin, and D. L. Garbers. 1989. The primary structure of a plasma membrane guanylate cyclase demonstrates diversity within this new receptor family. Cell. 58:1155-1162.

26. Ujiie, K., H. Nonoguchi, K. Tomita, and F. Marumo. 1990. Effects of ANF on cGMP synthesis in inner medullary collecting duct subsegments of rats. Am. J. Physiol. 259:F535-F538.

27. Martin, W., D. G. White, and A. H. Henderson. 1988. Endothelium-derived relaxing factor and atriopeptin II elevate cyclic GMP levels in pig aortic endothelial cells. Br. J. Pharmacol. 93:229-239.

28. Terada, Y., K. Tomita, H. Nonoguchi, and F. Marumo. 1992. Polymerase chain reaction localization of constitutive nitric oxide synthase and soluble guanylate cyclase messenger RNAs in microdissected rat nephron segments. J. Clin. Invest. 90:659-665.

29. Nonoguchi, H., M. A. Knepper, and V. C. Manganiello. 1987. Effects of atrial natriuretic factor on cyclic guanosine monophosphate and cyclic adenosine monophosphate accumulation in microdissected nephron segments from rats. $J$. Clin. Invest. 79:500-507. 